\title{
Dichloroacetate Inhibits Glycolysis and Augments Insulin-stimulated Glycogen Synthesis in Rat Muscle
}

\author{
Andrew S. Clark, William E. Mitch, Michael N. Goodman, Julie M. Fagan, M. Anwar Goheer, and Randall T. Curnow \\ Departments of Medicine, Physiology and Biophysics, Harvard Medical School, and Department of Medicine, Boston University School \\ of Medicine, Boston, Massachusetts 02115; and Departments of Medicine and Pharmacology, University of Virginia School \\ of Medicine, Charlottesville, Virginia 22908
}

\begin{abstract}
The decrease in plasma lactate during dichloroacetate (DCA) treatment is attributed to stimulation of lactate oxidation. To determine whether DCA also inhibits lactate production, we measured glucose metabolism in muscles of fed and fasted rats incubated with DCA and insulin. DCA increased glucose-6phosphate, an allosteric modifier of glycogen synthase, $\sim 50 \%$ and increased muscle glycogen synthesis and glycogen content $>25 \%$. Lactate release fell; inhibition of glycolysis accounted for $>\mathbf{8 0} \%$ of the decrease. This was associated with a decrease in intracellular AMP, but no change in citrate or ATP. When lactate oxidation was increased by raising extracellular lactate, glycolysis decreased $(r=-0.91)$, suggesting that lactate oxidation regulates glycolysis. When muscle lactate production was greatly stimulated by thermal injury, DCA increased glycogen synthesis, normalized glycogen content, and inhibited glycolysis, thereby reducing lactate release. The major effect of DCA on lactate metabolism in muscle is to inhibit glycolysis.
\end{abstract}

\section{Introduction}

Dichloroacetate (DCA) ${ }^{1}$ has been used to lower the blood lactate concentration in humans and experimental animals with lactic acidosis (1-4). This effect has been attributed to stimulation of pyruvate dehydrogenase activity, resulting in increased lactic acid oxidation (5-7). But, after examining the effects of DCA in hepatectomized dogs with lactic acidosis, Park and Arieff (2) concluded that DCA must have reduced lactate production in extrasplanchnic tissues. More recently, Graf et al. (3) measured muscle lactate concentration and hindlimb arteriovenous lactate differences in dogs with hypoxic lactic acidosis and concluded that DCA increased hepatic lactate extraction and reduced lactate production in skeletal muscle. This implies that DCA inhibits glycolysis in peripheral tissues, yet it was concluded that DCA did not reduce glycolysis in the rat hindquarter perfused without insulin (8). To identify how DCA affects insulin-stimulated glu-

Dr. Goodman's present address is Department of Endocrinology-Metabolism, University of California, Davis, CA 95616; Dr. Curnow's is E. I. DuPont, Biomedical Products, Caverly Mill Building, Barley Mills Plaza, Wilmington, DE 19898.

Address reprint requests to Dr. Mitch, Brigham and Women's Hospital, 75 Francis Street, Boston, MA 02115.

Received for publication 24 October 1985 and in revised form 10 October 1986.

1. Abbreviations used in this paper: DCA, dichloroacetate.

J. Clin. Invest.

(c) The American Society for Clinical Investigation, Inc.

0021-9738/87/02/0588/07 \$1.00

Volume 79, February 1987, 588-594 cose utilization in skeletal muscle, we measured the pathways of glucose metabolism in the presence and absence of DCA. DCA caused an inhibition of glycolysis and a stimulation of glycogen synthesis. The inhibition of glycolysis accounted for $>80 \%$ of the measured decrease in muscle lactate release. We also found that raising extracellular lactate can inhibit glycolysis so the effect of DCA does not depend on reducing intracellular lactate. Finally, we examined whether DCA would exert the same metabolic effects when the response of muscle to a catabolic condition, thermal injury, included accelerated glycolysis and depressed glycogen synthesis (9).

\section{Methods}

Male Sprague-Dawley rats weighing 180-220 g (Chaŕles River Breeding Laboratories, Inc., Wilmington, MA) were maintained on a 12-h light/ 12-h dark cycle and allowed free access to water and RMH 1000 rat chow (Agway Country Foods, Agway, Inc., Syracuse, NY) for at least 3 $\mathrm{d}$ before being studied. Fasted normal rats and rats with thermal injury and their controls were housed in individual wire-bottomed cages to prevent coprophagia and deprived of food and water for $44 \mathrm{~h}$ (10).

Epitrochlearis muscles were removed after anesthetizing rats with 5 $\mathrm{mg}$ of pentobarbital $/ 100 \mathrm{~g}$ of weight. The muscles were rinsed, blotted, weighed, and placed in individual flasks containing $3 \mathrm{ml}$ of Krebs-Henseleit bicarbonate buffer ( $\mathrm{pH} 7.4), 10 \mathrm{mM}$ glucose, $0.2 \%$ albumin, with or without $1 \mathrm{mM}$ DCA. Rubber stoppers were placed and the flasks were gassed through needles for $3 \mathrm{~min}$ with $95 \% \mathrm{O}_{2}-5 \% \mathrm{CO}_{2}$ and then placed in a rotating $60 \mathrm{cycle} / \mathrm{min}$ incubator $\left(37^{\circ} \mathrm{C}\right)$ for $30 \mathrm{~min}$ of preincubation. The muscles were removed, blotted, and transferred to flasks containing $3 \mathrm{ml}$ of the same media plus radiolabeled compounds and insulin as indicated, stoppered, regassed, and incubated for either $30 \mathrm{~min}$ or $2 \mathrm{~h}$.

To assess glucose transport, muscles were preincubated for $30 \mathrm{~min}$ in glucose-free media containing $10 \mathrm{mU} / \mathrm{ml}$ insulin and then transferred to flasks containing fresh media with $10 \mathrm{mM}$ glucose, a tracer amount of 2-deoxy-[U $\left.-{ }^{14} \mathrm{C}\right]$ glucose $(0.2 \mu \mathrm{M} ; 10 \mu \mathrm{Ci} / \mathrm{mmol}$ glucose $)$ and $10 \mathrm{mU} /$ $\mathrm{ml}$ insulin. After incubating for $\mathbf{3 0}$ minutes, the muscles were removed, blotted, homogenized in $1 \mathrm{ml}$ of $10 \%$ trichloroacetic acid (TCA), and centrifuged. The radioactivity in the supernatant was determined by liquid scintillation counting with correction for quenching using an external standard. The intracellular radioactivity was calculated using previously determined values of the water content and extracellular volume of the epitrochlearis muscle (10). Glucose transport was calculated by dividing the intracellular radioactivity by the ratio of 2 -deoxy- $\left[\mathrm{U}-{ }^{14} \mathrm{C}\right] \mathrm{glucose}$ to glucose in the media. In other experiments, tracer amounts of both 2 deoxy-[U- $\left.-{ }^{14} \mathrm{C}\right]$ glucose and $\left[2-{ }^{3} \mathrm{H}\right]$ glucose $(0.1 \mathrm{mCi} / \mathrm{mmol}$ glucose $)$ were added to media containing $10 \mathrm{mM}$ glucose and $10 \mathrm{mU} / \mathrm{ml}$ insulin in order to compare rates of transport and glucose phosphorylation. Previously, we showed that 2 -deoxy-[U- $\left.{ }^{14} \mathrm{C}\right]$ glucose transport into epitrochlearis muscles corresponds closely to the rate of ${ }^{3} \mathrm{H}_{2} \mathrm{O}$ formed from $\left[2-{ }^{3} \mathrm{H}\right]$ glucose $(9)$. The formation of ${ }^{3} \mathrm{H}_{2} \mathrm{O}$ was measured because it is an index of the rate of glucose phosphorylation (11) and corresponds closely to glucose uptake by perfused muscle (12).

Glucose utilization. Glucose utilization was assessed by incubating muscles for $2 \mathrm{~h}$ with $2 \mu \mathrm{Ci} / \mathrm{mmol}\left[\mathrm{U}-{ }^{14} \mathrm{C}\right.$ ]glucose, $0.1 \mathrm{mCi} / \mathrm{mmol}$ [5$\left.{ }^{3} \mathrm{H}\right]$ glucose, and $10 \mathrm{mM}$ glucose. Glucose oxidation, lactate release, and tyrosine release, as a measure of the net rate of protein degradation, were 
calculated as described previously $(9,10)$. Tritiated water in the media was measured as described by Ashcroft et al. (13); recovery of ${ }^{3} \mathrm{H}_{2} \mathrm{O}$ was measured with each experiment and averaged $73 \pm 2 \%$. The muscle was dissolved in $0.5 \mathrm{ml}$ of $30 \% \mathrm{KOH}$ at $100^{\circ} \mathrm{C}$ and glycogen was determined colorimetrically; recovery of glycogen was $91 \pm 2 \%$ (14). The ${ }^{14} \mathrm{C}$ and ${ }^{3} \mathrm{H}$ in glycogen were determined, and glycogen synthesis was calculated using the specific radioactivity of $\left[5-{ }^{3} \mathrm{H}\right]-$ and $\left[\mathrm{U}-{ }^{14} \mathrm{C}\right] \mathrm{glucose}$ in the media (9).

Glucose uptake was calculated as $\left[5-{ }^{3} \mathrm{H}\right]$ glucose incorporated into glycogen plus ${ }^{3} \mathrm{H}_{2} \mathrm{O}$ formed during glycolysis (9). Net glycolysis was calculated as the difference between the rate of ${ }^{3} \mathrm{H}_{2} \mathrm{O}$ formed and substrate recycling (15). Substrate cycling was calculated as the difference between the rates of glycogen synthesis from $\left[\mathrm{U}-{ }^{14} \mathrm{C}\right]$ glucose and $\left[5-{ }^{3} \mathrm{H}\right]$ glucose $(16,17)$. This method yields values (9) similar to those measured in incubated epitrochlearis muscles by Challis et al. (17) who calculated substrate cycling from the ${ }^{3} \mathrm{H} /{ }^{14} \mathrm{C}$ ratio of fructose-1,6-diphosphate.

The effects of DCA on muscle glycogen synthase and phosphorylase activities were measured after incubating in $10 \mathrm{mM}$ glucose, with or without $10 \mathrm{mU} / \mathrm{ml}$ insulin for $45 \mathrm{~min}$. Enzyme activities are expressed per milliliter of muscle homogenate; the activity ratio of glycogen synthase $(\% \mathrm{I})$ is the ratio of enzyme activity measured without to that measured with $10 \mathrm{mM}$ glucose-6-phosphate (18). The activity ratio of glycogen phosphorylase (\%a) was calculated as the ratio of enzyme activity measured without to that measured with 0.1 M AMP (19). In separate experiments, muscles incubated under similar conditions were homogenized in $1 \mathrm{ml}$ of $5 \%$ perchloric acid and assayed enzymatically for glucose-6phosphate (20).

The effects of lactate on glucose and lactate metabolism were assessed in muscles preincubated with $10 \mathrm{mM}$ glucose and $10 \mathrm{mU} / \mathrm{ml}$ insulin. The muscles were transferred to flasks with fresh media containing 10 $\mathrm{mM}$ glucose, $10 \mathrm{mU} / \mathrm{ml}$ insulin, different concentrations of lactate, [5$\left.{ }^{3} \mathrm{H}\right]$ glucose $(0.2 \mathrm{mCi} / \mathrm{mmol}$ glucose $)$ and $\left[1-{ }^{14} \mathrm{C}\right]$ lactate $(5 \mu \mathrm{Ci} / \mathrm{mmol}$ lactate), and incubated for $2 \mathrm{~h}$. Lactate oxidation and glycogen synthesis from lactate were calculated as the rate of ${ }^{14} \mathrm{CO}_{2}$ released and ${ }^{14} \mathrm{C}$ incorporated into glycogen, respectively, divided by the specific radioactivity of lactate in the media. The sum of these rates was used to estimate lactate uptake. Glycogen synthesis from glucose was calculated from the
${ }^{3} \mathrm{H}$ content of glycogen divided by the specific radioactivity of [5$\left.{ }^{3} \mathrm{H}\right]$ glucose in the media. In preliminary experiments, we found that substrate cycling in the presence of $10 \mathrm{mM}$ lactate was $<8 \%$ of the rate of glycogen synthesis from glucose, so lactate has only a minimal influence on the measurement of glycogen synthesis from glucose. Glycolysis was calculated from the rate of ${ }^{3} \mathrm{H}_{2} \mathrm{O}$ formed and glucose uptake was calculated as the sum of glycogen synthesis from glucose plus glycolysis.

In separate experiments, intracellular citrate (21), ATP, and AMP (14) concentrations were measured. Muscles were incubated with 10 $\mathrm{mM}$ glucose, $10 \mathrm{mU} / \mathrm{ml}$ insulin with or without $1 \mathrm{mM} \mathrm{DCA}$. In another experiment, muscles were preincubated with $10 \mathrm{mM}$ glucose and 10 $\mathrm{mU} / \mathrm{ml}$ insulin, and then incubated in the same media with or without $8 \mathrm{mM}$ lactate.

To evaluate the metabolic fate of $\left[2-{ }^{3} \mathrm{H}\right]$ glucose, lactate, pyruvate, and alanine released by muscle were isolated by adding $2 \mathrm{ml}$ of media to a $4 \times 0.5-\mathrm{cm}$ column of AG1-4 $\times$ anion exchange resin (Biorad Laboratories, Richmond, CA) and washing the column with $20 \mathrm{ml}$ of $\mathrm{H}_{2} \mathrm{O}$. The glycolytic products were eluted with $2 \mathrm{ml}$ of $2 \mathrm{M}$ saline and the radioactivity in these products was determined by scintillation counting.

Radiolabeled chemicals were obtained from New England Nuclear (Boston, MA). Reagent grade chemicals, enzymes and fatty acid, and globulin-free albumin were purchased from Sigma Chemical Co. (St. Louis, MO). Porcine insulin was obtained from Eli Lilly \& Co. (Indianapolis, IN) and DCA from Fisher Scientific Co. (Silver Spring, MD).

Results are presented as mean \pm SEM. A paired $t$ test was used to assess the effects of DCA in incubations of muscles from individual rats. An unpaired $t$ test was used to compare results that were obtained from muscles of rats in different treatment groups or incubated at different concentrations of lactate or insulin. Results were considered significant at $P<0.05$.

\section{Results}

The effects of $1 \mathrm{mM}$ DCA on the different pathways of insulinmediated glucose metabolism in muscles from fed and fasted rats are shown in Fig. 1. There was a small (18\%), but significant,
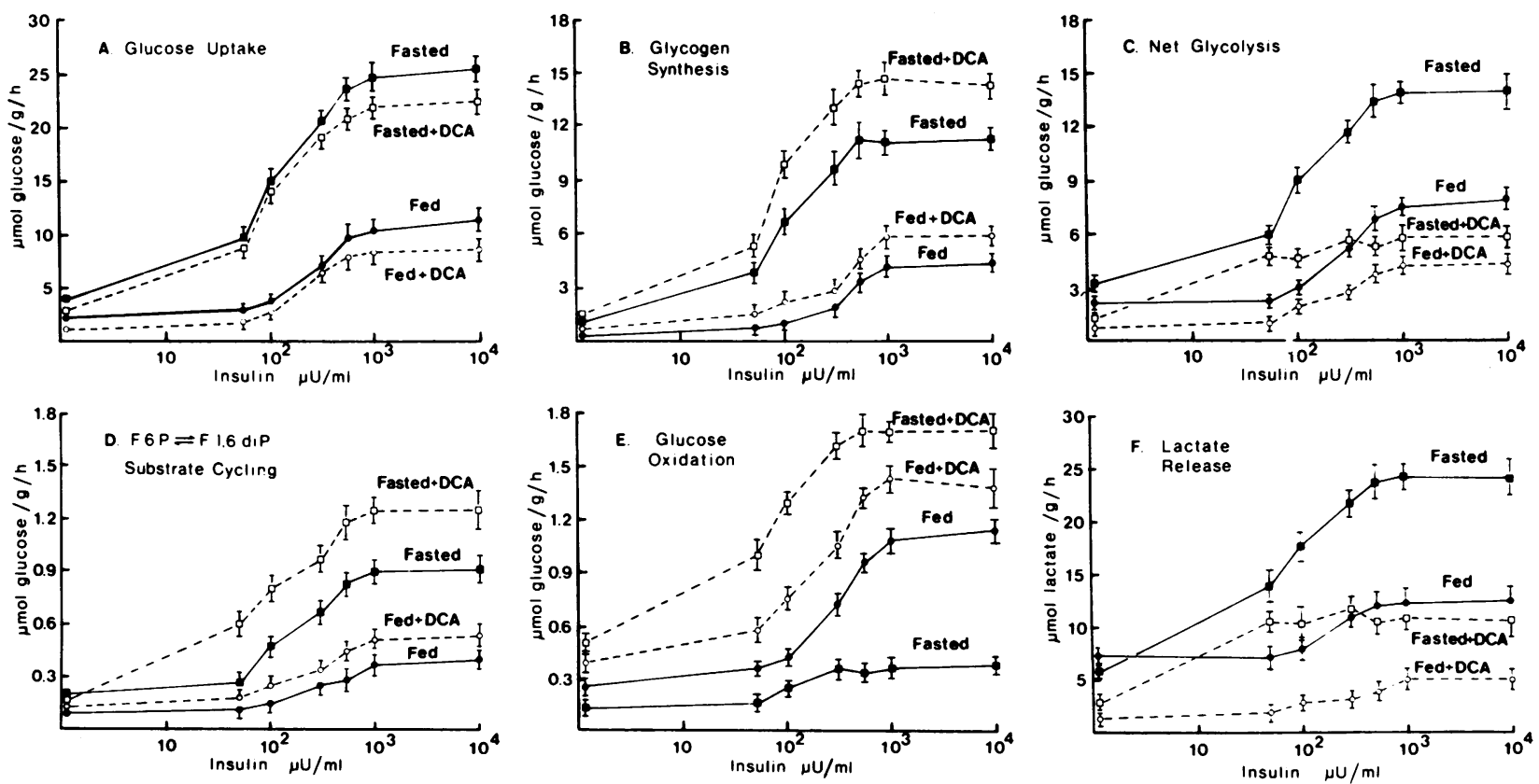

Figure 1. The dose-response relationships between insulin concentration and $(A)$ glucose uptake, $(B)$ glycogen synthesis, $(C)$ net glycolysis, $(D)$ substrate cycling between fructose-6-phosphate and fructose-1,6diphosphate, $(E)$ glucose oxidation, and $(F)$ lactate release are shown. Values are mean \pm SEM of paired muscles taken from six to eight fed (circles) or fasted (squares) rats incubated for $2 \mathrm{~h}$ at each concentra- tion of insulin, with (dashed line) or without (solid line) $1 \mathrm{mM}$ DCA. Significant $(P<0.05)$ differences between muscles incubated with DCA and the appropriate control are indicated by showing both upper and lower standard error bars. The media contained $10 \mathrm{mM}$ glucose, [U- ${ }^{14} \mathrm{C}$ ]glucose $(5 \mu \mathrm{Ci} / \mathrm{mMol})$ and $\left[5-{ }^{3} \mathrm{H}\right] \mathrm{glucose}(0.1 \mathrm{mCi} / \mathrm{mMol})$. The calculations of the different rates are described in Methods. 
decrease in the maximal rate of glucose uptake, but otherwise, DCA did not change insulin-stimulated glucose uptake in muscles of fed and fasted rats (Fig. $1 A$ ). A more pronounced change caused by DCA was the increase in glycogen synthesis in muscles from fasted rats at all levels of insulin and in muscles of fed rats when insulin exceeded $500 \mu \mathrm{U} / \mathrm{ml}$ (Fig. $1 \mathrm{~B}$ ). The most dramatic effect of DCA was to inhibit net glycolysis. This occurred both with and without insulin (Fig. $1 C$ ). The decrease in net glycolysis was accompanied by increased substrate cycling of fructose-1,6diphosphate to fructose-6-phosphate (Fig. $1 D$ ), but this accounted for $<10 \%$ of the decrease in net glycolysis. In the absence of insulin, DCA stimulated glucose oxidation by $40 \%$ in muscles of fed rats and about threefold in muscles of fasted rats (Fig. 1 $E)$. At the maximal concentration of insulin, DCA increased muscle glucose oxidation by $30 \%$ in fed rats and about fivefold in fasted rats. Lactate release (Fig. $1 F$ ) was sharply reduced at all concentrations of insulin. In the absence of insulin, it was calculated that glucose oxidation could account for only $5 \%$ and $30 \%$ of the DCA-induced decrease in lactate release from muscles of fed and fasted rats, respectively. In the presence of $10 \mathrm{mU} /$ $\mathrm{ml}$ insulin, DCA decreased muscle lactate release $64 \%$ in fed rats $(-7.6 \pm 0.7 \mu \mathrm{mol} / \mathrm{g}$ per $\mathrm{h} ; P<0.01)$ and $59 \%(-13.4 \pm 0.9$ $\mu \mathrm{mol} / \mathrm{g}$ per $\mathrm{h} ; P<0.01)$ in fasted rats. Because glucose oxidation was increased by only $0.5-1.5 \mu \mathrm{mol} / \mathrm{g}$ per $\mathrm{h},>80 \%$ of the decrease in lactate release caused by DCA resulted from inhibition of net glycolysis.

To study the mechanism by which DCA reduced glucose uptake at supraphysiologic levels of insulin, glucose transport and phosphorylation were measured in muscles of fasted rats using 2-deoxy-[U-14 C]glucose and $\left[2-{ }^{3} \mathrm{H}\right]$ glucose $(9,11,12)$. With $10 \mathrm{mU} / \mathrm{ml}$ insulin, rates of glucose transport and phosphorylation were the same (Table I); when DCA was added, 2-deoxy$\left[\mathrm{U}-{ }^{14} \mathrm{C}\right] \mathrm{glucose}$ transport was unchanged, but glucose phosphorylation (the rate of ${ }^{3} \mathrm{H}_{2} \mathrm{O}$ formed) was decreased $17 \%$ after $30 \mathrm{~min}$ and $12 \%$ after $2 \mathrm{~h}$ of incubation. The change at $2 \mathrm{~h}$ was accompanied by an increased intracellular concentration of ${ }^{3} \mathrm{H}$ labeled compounds. Both in the presence and absence of DCA, the quantity of ${ }^{3} \mathrm{H}$ contained in acid-precipitable material and that recovered as lactate, pyruvate, and alanine amounted to $<1 \%$ of the total quantity of ${ }^{3} \mathrm{H}$ recovered (data not shown). If the intracellular concentration of $\left[2-{ }^{3} \mathrm{H}\right]$ glucose- 6 -phosphate had risen, as would occur if the conversion of glucose-6-phosphate to fructose-6-phosphate were inhibited, the ${ }^{3} \mathrm{H}$ content of glycogen should have increased because DCA stimulated glycogen synthesis (Fig. $1 B$ ). Because the ${ }^{3} \mathrm{H}$ content of glycogen did not change with DCA, it is likely that the ${ }^{3} \mathrm{H}$ in the soluble fraction was $\left[2-{ }^{3} \mathrm{H}\right] \mathrm{glucose}$. Thus, the small inhibition of maximal insulinstimulated glucose uptake measured in the presence of DCA (Fig. $1 A$ ) must have been due to impaired glucose phosphorylation.

The increase in muscle glycogen synthesis induced by DCA (Fig. $1 B$ ) has not been reported previously. To determine whether this was accompanied by an increase in glycogen content, muscle glycogen was measured after $2 \mathrm{~h}$ of incubation. In the presence of $10 \mathrm{mU} / \mathrm{ml}$ of insulin, DCA increased the muscle glycogen content $25 \%$ in fed rats and $31 \%$ in fasted rats (Table II). In the absence of insulin, DCA had no effect on muscle glycogen synthesis (Fig. $1 B$ ) or glycogen content (Table II).

To study the mechanism by which DCA increased glycogen synthesis, we measured the activity of muscle glycogen synthase and phosphorylase. DCA did not change either the activation of glycogen synthase by insulin or the activity of glycogen phosphorylase (Table III). However, in the presence of insulin, DCA increased the intracellular concentration of glucose-6-phosphate, an allosteric modifier of glycogen synthase (22), by $\sim 50 \%$.

Because DCA causes a marked decrease in extracellular lactate (1-4), we also measured the concentration-effect relationship between extracellular lactate and insulin-stimulated glucose and lactate metabolism in muscle. In the absence of DCA, the rates of lactate uptake, incorporation into glycogen, and oxidation increased as the extracellular concentration of lactate was raised (Fig. 2). Fasting greatly reduced the capacity for muscle to utilize extracellular lactate. As the lactate concentration was raised, glycogen synthesis increased $\sim 30 \%$ and glycolysis decreased. With feeding, glycolysis was inhibited at a physiologic concentration of lactate $(2 \mathrm{mM})$. In fasted rats, glycolysis was not inhibited until the extracellular lactate concentration exceeded 4 $\mathrm{mM}$. In individual muscles of fed and fasted rats, the rate of glycolysis was inversely proportional to the rate of lactate oxidation $(r=-0.91 ; y=-0.50 x+4.97)$. These results and those obtained with DCA indicate that a high lactate oxidation rate is closely linked to a reduced rate of glycolysis.

The inhibitory effect of DCA and extracellular lactate on glycolysis could be caused by changes in intracellular ATP, AMP,

Table I. Effects of DCA on Insulin-stimulated Transport and Phosphorylation of Glucose in Incubated Epitrochlearis Muscles

\begin{tabular}{|c|c|c|c|c|c|}
\hline & \multirow[b]{2}{*}{ Glucose transport } & \multirow[b]{2}{*}{ Phosphorylation } & \multicolumn{3}{|c|}{${ }^{3} \mathrm{H}$ recovery from $\left[2-{ }^{3} \mathrm{H}\right]$ glucose } \\
\hline & & & ${ }^{3} \mathrm{H}_{2} \mathrm{O}$ & Glycogen & Soluble fraction \\
\hline & $\mu \mathrm{mol} / \mathrm{g}$ per $h$ & $\mu \mathrm{mol} / \mathrm{g}$ per $h$ & $\mu \mathrm{mol} / \mathrm{g}$ per $h$ & $\mu \mathrm{mol} / \mathrm{g}$ per $h$ & $\mathrm{nmol} / \mathrm{ml}$ \\
\hline Without DCA & $26.62 \pm 2.08$ & $26.14 \pm 1.96$ & $25.57 \pm 1.17$ & $0.43 \pm 0.07$ & $212 \pm 136$ \\
\hline With DCA & $24.66 \pm 2.06$ & $21.82 \pm 2.13^{*}$ & $22.66 \pm 0.70^{*}$ & $0.47 \pm 0.05$ & $669 \pm 135^{*}$ \\
\hline
\end{tabular}

Values are the mean \pm SEM from muscles of eight rats fasted for $48 \mathrm{~h}$. Muscles were preincubated for 30 min in glucose-free, Krebs-Henseleit buffer containing $10 \mathrm{mU} / \mathrm{ml}$ insulin and then transferred to flasks containing $10 \mathrm{mM}$ glucose, $10 \mathrm{mU} / \mathrm{ml}$ insulin, $2-$ deoxy-[U- $\left.{ }^{14} \mathrm{C}\right]$ glucose $(0.2 \mu \mathrm{M}$, $10 \mu \mathrm{Ci} / \mathrm{mmol}$ glucose $)$ and $\left[2{ }^{3} \mathrm{H}\right]$ glucose $(0.1 \mathrm{mCi} / \mathrm{mmol}$ glucose). Rates of glucose transport and phosphorylation, respectively, were measured during a 30-min experimental incubation. In separate experiments, the content of ${ }^{3} \mathrm{H}$ in media water, muscle glycogen, and intracellular metabolites after 2-h incubations with $\left[2-{ }^{3} \mathrm{H}\right]$ glucose, $10 \mathrm{mM}$ glucose, and $10 \mathrm{mU} / \mathrm{ml}$ insulin were measured. Previously determined values (10) for the inulin space of epitrochlearis muscles were used to calculate the intracellular concentration of radiolabeled glucose metabolites. The results are corrected for the specific radioactivity of $\left[2-{ }^{3} \mathrm{H}\right]$ glucose in the media. ${ }^{*} P<0.01$ by paired $t$ test compared with contralateral muscles incubated without $1 \mathrm{mM}$ DCA. 
Table II. Effects of DCA on the Concentration of Glycogen in Incubated Muscles

\begin{tabular}{llll}
\hline & \multicolumn{3}{l}{ Glycogen concentration } \\
\cline { 2 - 4 } Rats & \multicolumn{3}{c}{ Final } \\
\cline { 2 - 4 } & Initial & 0 & With insulin \\
\hline & $\mu \mathrm{mol} / \mathrm{g}$ & $\mu \mathrm{mol} / \mathrm{g}$ & $\mu \mathrm{mol} / \mathrm{g}$ \\
Fed & & & \\
$\quad$ Without DCA & $26.1 \pm 1.0$ & $27.8 \pm 1.2$ & $35.3 \pm 1.1$ \\
$\quad$ With DCA & $25.2 \pm 2.1$ & $27.4 \pm 2.0$ & $44.1 \pm 1.9^{*}$ \\
Fasted & & & \\
$\quad$ Without DCA & $18.1 \pm 1.2$ & $19.9 \pm 1.8$ & $39.7 \pm 2.7$ \\
$\quad$ With DCA & $19.1 \pm 1.8$ & $21.3 \pm 2.3$ & $52.2 \pm 2.6^{*}$ \\
& & & \\
\hline
\end{tabular}

Values are mean \pm SEM of muscles taken from 6-12 fed and fasted rats. The concentration of glycogen was measured after a 30-min preincubation ("initial") and after a 2-h experimental incubation in media containing $10 \mathrm{mM}$ glucose and 0 or $10 \mathrm{mU} / \mathrm{ml}$ insulin. * $P<0.01$ by paired $t$ test compared with muscles incubated without 1 mM DCA.

or citrate concentrations $(23,24)$. Intracellular AMP decreased $23 \%$ during incubation with DCA or lactate, though the change was significant $(P<0.05)$ only with DCA (Table IV). There were no significant changes in intracellular ATP or citrate during incubation with DCA or lactate. Intracellular lactate fell $71 \%$ with DCA and increased more than twofold when muscles were incubated with $8 \mathrm{mM}$ lactate.

Previously, we found that thermal injury stimulated lactate production by inhibiting glycogen synthesis and increasing glycolysis in muscles distant from the site of injury (9). The results in Fig. 1 suggest that DCA should counteract this response. To examine this possibility, we measured the effects of DCA on insulin-mediated metabolism in muscles of burned rats incubated with a physiologic $(2 \mathrm{mM})$ or supraphysiologic $(10 \mathrm{mM})$ concentration of lactate. The pattern of response to DCA in these muscles differed from that in control muscles. Increasing the concentration of extracellular lactate inhibited insulin-stimulated muscle glycolysis by $46 \%$ in normal fasted rats, but it did not inhibit the accelerated glycolysis occurring in muscles of burned rats (Table V). This difference in glycolytic rates occurred despite the fact that lactate oxidation was increased fivefold in muscles from both groups of rats.
To estimate net lactate production, the sum of the rates of lactate incorporated into glycogen and oxidized were subtracted from two times the rate of glycolysis. Based on this calculation, increasing extracellular lactate from 2 to $10 \mathrm{mM}$ inhibited lactate production from muscles of control rats by $56 \%$. In muscles of burned rats, this effect was partially lost in that the decrease was only $22 \%$. In muscles from both groups of rats, raising extracellular lactate increased the glycogen content of muscles (Table V).

The addition of DCA to incubated muscles of burned and control rats had four major effects on insulin-stimulated metabolism (Table V). With $2 \mathrm{mM}$ lactate, DCA increased lactate oxidation, glycogen synthesis, and glycogen content, and it decreased glycolysis in muscles of both groups of rats. With 10 $\mathrm{mM}$ lactate, DCA also stimulated lactate oxidation and inhibited glycolysis, but glycogen synthesis and the glycogen content of muscle were increased by DCA only in burned rats. Finally, with $2 \mathrm{mM}$ lactate, DCA decreased net lactate release by 20 $\mu \mathrm{mol} / \mathrm{g}$ per $\mathrm{h}$ in muscles of both control and burned rats; inhibition of glycolysis accounted for $\sim 90 \%$ of the decrease in both groups of muscles. When muscles were incubated with a supraphysiologic $(10 \mathrm{mM})$ concentration of lactate, the combined actions of DCA to reduce glycolysis and accelerate lactate oxidation led to a net removal of $1.8 \mu \mathrm{mol}$ lactate $/ \mathrm{g}$ per $\mathrm{h}$ from the media in control rats; net release of lactate by muscles of burned rats was reduced to only $0.5 \mu \mathrm{mol}$ lactate $/ \mathrm{g}$ per $\mathrm{h}$.

From our previous results linking proteolysis to the stimulation of lactate release $(9,25,26)$, we expected that DCA would reduce muscle proteolysis. Neither DCA nor raising extracellular lactate changed the rate of net protein degradation (data not shown).

\section{Discussion}

In this study, we have identified important changes in muscle metabolism that pertain to the beneficial effects of DCA in conditions associated with excessive accumulation of lactate (1-4). As expected $(7,8)$, DCA stimulated glucose and lactate oxidation in skeletal muscle (Fig. 1, Table V). A much more important effect was that DCA inhibited glycolysis; this accounted for $>80 \%$ of the decrease in lactate release observed in muscles of fed or starved rats incubated with insulin. To examine whether the depression of glycolysis was due to changes in intracellular lactate, we incubated muscles with increasing extracellular lactate concentrations and found that this also reduced glycolysis, sug-

Table III. Effects of DCA on Glycogen Synthase and Phosphorylase Activity Ratios and on Glucose-6-phosphate Concentrations in Muscle

\begin{tabular}{|c|c|c|c|c|c|c|}
\hline & \multicolumn{2}{|c|}{ Glycogen synthase (activity ratio) } & \multicolumn{2}{|c|}{ Glycogen phosphorylase (activity ratio) } & \multicolumn{2}{|c|}{ Glucose-6-phosphate } \\
\hline & Without insulin & With insulin & Without insulin & With insulin & Without insulin & With insulin \\
\hline & $\%$ & $\%$ & $\%$ & $\%$ & $\mathrm{nmol} / \mathrm{g}$ & $\mathrm{nmol} / \mathrm{g}$ \\
\hline Without DCA & $34.2 \pm 2.0$ & $52.3 \pm 2.8^{*}$ & $15.9 \pm 1.7$ & $19.2 \pm 1.5$ & $292 \pm 21$ & $318 \pm 20$ \\
\hline With DCA & $35.9 \pm 2.8$ & $54.8 \pm 2.4^{*}$ & $14.6 \pm 1.5$ & $18.6 \pm 1.3$ & $338 \pm 24$ & $498 \pm 19^{\ddagger}$ \\
\hline
\end{tabular}

Values are the mean \pm SEM of muscles taken from 5-10 rats fasted for $48 \mathrm{~h}$. Paired muscles were incubated with or without $1 \mathrm{mM}$ DCA for a 45 min experimental period either in the absence or presence of $10 \mathrm{mU} / \mathrm{ml}$ insulin. Muscles were then homogenized and assayed immediately for glycogen synthase and phosphorylase activity. In separate experiments, glucose-6-phosphate concentrations were measured enzymatically. $* P$ $<0.01$ by unpaired $t$ test compared with values obtained from muscles incubated without insulin. $\$ P<0.005$ by paired $t$ test compared with muscles incubated without DCA. 

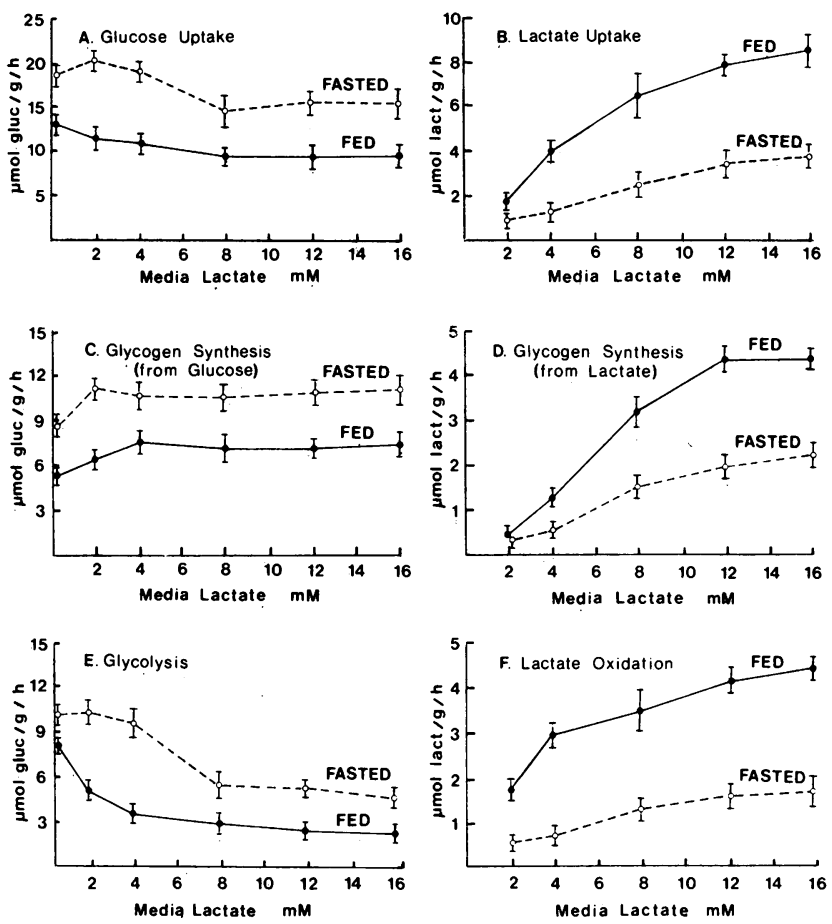

Figure 2. The dose-response relationship between lactate concentration and $(A)$ glucose uptake, $(B)$ lactate uptake calculated as the sum of glycogen synthesis from lactate plus lactate oxidation, $(C)$ glycogen synthesis from glucose, $(D)$ glycogen synthesis from lactate, $(E)$ glycolysis, and $(F)$ lactate oxidation are shown. Values are mean \pm SEM of muscles from five fed (solid line) and five fasted (dashed line) rats studied at each concentration of lactate. Significant $(P<0.05)$ differences between muscles of fed and fasted rats are indicated by showing both upper and lower standard error bars. The media contained 10 $\mathrm{mM}$ glucose, $10 \mathrm{mU} / \mathrm{ml}$ insulin, $\left[5{ }^{3} \mathrm{H}\right]$ glucose $(0.1 \mathrm{mCi} / \mathrm{mmol})$, [1${ }^{14} \mathrm{C}$ lactate $(5 \mu \mathrm{Ci} / \mathrm{mmol}$ lactate), and different concentrations of lactate as indicated.

gesting that lactate may, in fact, regulate its own metabolism. However, both DCA treatment, which decreases intracellular lactate (Table IV), and raising extracellular lactate (Fig. 2) stimulate lactate oxidation, as well as inhibit glycolysis. This suggests that the metabolic changes caused by DCA are dependent upon flux through the tricarboxylic acid cycle rather than the intracellular concentration of lactate. One potential mechanism for this effect would be an increase in intracellular levels of citrate or ATP, or a decrease in the AMP concentration inasmuch as these changes in metabolites decrease the in vitro activity of phosphofructokinase $(23,24)$. Incubation with DCA or a high extracellular lactate concentration did reduce intracellular AMP but did not change the ATP or citrate concentrations. Whether this change in intracellular AMP caused the metabolic effects of DCA is uncertain because there was no significant change in the ATP/AMP ratio (24). Thus, the exact mechanism for the inhibitory effect of DCA on glycolysis remains speculative, but our results indicate that this inhibition is quantitatively the most important effect of the drug on lactate metabolism in skeletal muscle.

We also identified another metabolic change induced by DCA, increased glycogen synthesis in muscle. To examine mechanisms that might explain this, we measured the activities of the enzymes regulating glycogen turnover. DCA did not change the activities of muscle glycogen synthase or phosphorylase nor did it augment the activation of glycogen synthase by insulin. DCA did, however, cause a 50\% increase in the intracellular concentration of glucose-6-phosphate. This has been shown to cause allosteric modification of glycogen synthase in muscle (22) and could account for the increase in glycogen synthesis (Fig. 1). The significance of this was emphasized by the finding that DCA increased the glycogen content of muscle (Table II). Similar metabolic changes were demonstrated when muscle lactate production was stimulated as part of the response to thermal injury (Table V). Compared with control rats, burned rats had a different pattern of muscle glucose and lactate metabolism and a different response to raising extracellular lactate. In spite of this, DCA completely corrected the defect in glycogen synthesis, increased the glycogen content of muscle, and substantially reduced lactate release. Again, decreased lactate release was primarily due to inhibition of glycolysis.

The decrease in insulin-stimulated glucose uptake measured during incubation with DCA (Fig. 1) seemed to be caused by impaired glucose phosphorylation (Table I). An increase in intracellular glucose-6-phosphate (Table III) could decrease the activity of hexokinase (27). This could limit insulin-stimulated glucose phosphorylation (Table I). The fact that glucose-6-phosphate levels are increased despite impaired glucose phosphorylation must mean that DCA inhibited glycolysis to a greater extent than it inhibited glucose phosphorylation.

The physiologic significance of the decrease in muscle glucose uptake that we found is unclear because the blood glucose of animals or humans given DCA is unchanged or decreased (1, $2,8,28-30)$. The hypoglycemic effect of DCA has been attributed to direct inhibition of hepatic gluconeogenesis $(31,32)$ and to decreased net release of gluconeogenic precursors from peripheral tissues $(28,30,31,33)$. Diamond et al. (30) used the insulin clamp technique to study the effect of DCA in fasted dogs. They concluded that DCA increased glucose clearance by peripheral

Table IV. Effect of DCA or Increased Extracellular Lactate on Tissue Metabolites in Incubated Epitrochlearis Muscles

\begin{tabular}{|c|c|c|c|c|c|}
\hline & Addition & ATP & AMP & Citrate & Lactate \\
\hline & & nmol/mg muscle & nmol/mg muscle & nmol/mg muscle & nmol/mg muscle \\
\hline Control & - & $4.53 \pm 0.19$ & $0.124 \pm 0.011$ & $0.165 \pm 0.014$ & $1.94 \pm 0.13$ \\
\hline Change & $1 \mathrm{mM}$ DCA & $-0.57 \pm 0.27$ & $-0.029 \pm 0.012^{*}$ & $+0.003 \pm 0.015$ & $-1.36 \pm 0.16^{\ddagger}$ \\
\hline Control & - & $4.76 \pm 0.15$ & $0.109 \pm 0.010$ & $0.143 \pm 0.015$ & $1.63 \pm 0.06$ \\
\hline Change & $8 \mathrm{mM}$ lactate & $-0.41 \pm 0.25$ & $-0.025 \pm 0.013$ & $+0.005 \pm 0.016$ & $+3.77 \pm 0.29^{\ddagger}$ \\
\hline
\end{tabular}

Values are mean \pm SEM from muscles of at least five rats in each group. Paired muscles were incubated with $10 \mathrm{mM} \mathrm{glucose,} 10 \mathrm{mU} / \mathrm{ml}$ insulin with or without $1 \mathrm{mM}$ DCA, or with or without $8 \mathrm{mM}$ lactate. ${ }^{*} P<0.05 ;{ }^{\ddagger} P<0.01$ by paired analysis. 
Table V. Effects of DCA and Lactate on Insulin-mediated Glucose, and Lactate Metabolism in Incubated Skeletal Muscle of Burned and Control Rats

\begin{tabular}{|c|c|c|c|c|c|}
\hline & \multirow{2}{*}{$\begin{array}{l}\text { Lactate } \\
\text { concentration }\end{array}$} & \multicolumn{2}{|l|}{ Burned } & \multicolumn{2}{|l|}{ Control } \\
\hline & & Without DCA & With DCA & Without DCA & With DCA \\
\hline & $m M$ & & & & \\
\hline \multirow[t]{2}{*}{ Glycogen synthesis from glucose ( $\mu \mathrm{mol}$ glucose $/ \mathrm{g}$ per $h$ ) } & 2 & $8.65 \pm 0.90$ & $13.80 \pm 1.05^{*}$ & $12.15 \pm 1.03$ & $16.06 \pm 0.78^{*}$ \\
\hline & 10 & $11.67 \pm 0.78^{\ddagger}$ & $16.03 \pm 0.88^{*}$ & $14.09 \pm 0.75$ & $14.85 \pm 0.85$ \\
\hline \multirow[t]{2}{*}{ Glycolysis ( $\mu \mathrm{mol}$ glucose/g per $h$ ) } & 2 & $15.60 \pm 0.76$ & $4.16 \pm 0.51^{*}$ & $12.34 \pm 0.87$ & $3.41 \pm 0.37^{*}$ \\
\hline & 10 & $13.36 \pm 1.32$ & $2.60 \pm 0.18^{* \pm}$ & $6.65 \pm 0.95^{\ddagger}$ & $1.60 \pm 0.15^{* \ddagger}$ \\
\hline \multirow[t]{2}{*}{ Lactate oxidation ( $\mu \mathrm{mol}$ lactate $/ g$ per $h$ ) } & 2 & $0.35 \pm 0.02$ & $2.21 \pm 0.08^{*}$ & $0.40 \pm 0.04$ & $2.67 \pm 0.11^{*}$ \\
\hline & 10 & $1.54 \pm 0.25^{\ddagger}$ & $4.23 \pm 0.30^{* \ddagger}$ & $1.75 \pm 0.08^{\ddagger}$ & $3.97 \pm 0.20^{* \neq}$ \\
\hline \multirow[t]{2}{*}{ Net lactate release ( $\mu$ mol lactate/g per $h$ ) } & 2 & $30.45 \pm 1.86$ & $6.13 \pm 0.75$ & $24.29 \pm 1.94$ & $4.12 \pm 0.52$ \\
\hline & 10 & $23.74 \pm 2.61$ & $0.49 \pm 0.08^{\ddagger}$ & $10.72 \pm 1.32^{\ddagger}$ & $-1.78 \pm 0.26^{\ddagger}$ \\
\hline \multirow[t]{2}{*}{ Glycogen content $(\mu \mathrm{mol} / \mathrm{g})$} & 2 & $37.2 \pm 3.2$ & $46.2 \pm 2.1^{*}$ & $47.9 \pm 2.8$ & $59.1 \pm 3.3^{*}$ \\
\hline & 10 & $49.3 \pm 4.1^{\ddagger}$ & $59.3 \pm 5.1^{* \ddagger}$ & $57.2 \pm 2.3^{\ddagger}$ & $62.1 \pm 2.2$ \\
\hline
\end{tabular}

Values are the mean \pm SEM of muscles taken from six-eight rats in each group; all rats were fasted for $44 \mathrm{~h}$. Muscles were preincubated in media containing $10 \mathrm{mM}$ glucose with or without $1 \mathrm{mM} \mathrm{DCA}$ and incubated in media containing $10 \mathrm{mM}$ glucose, $10 \mathrm{mU} / \mathrm{ml}$ insulin, $2 \mathrm{or} 10 \mathrm{mM}$ lactate as indicated, $\left[5-{ }^{3} \mathrm{H}\right]$ glucose $(0.2 \mathrm{mCi} / \mathrm{mmol}$ glucose $)$ and $\left[1-{ }^{14} \mathrm{C}\right]$ lactate $(5 \mu \mathrm{Ci} / \mathrm{mmol}$ lactate $)$ with or without $1 \mathrm{mM}$ DCA. The metabolism of glucose and lactate and glycogen content were measured as described in Methods. Net lactate release from individual muscles was calculated as two times glycolysis minus the sum of lactate oxidation plus glycogen synthesis from lactate. ${ }^{*} P<0.05$ by paired analysis compared with muscles incubated without DCA. ${ }^{\ddagger} P<0.05$ by unpaired $t$ test compared with muscles incubated in $2 \mathrm{mM}$ lactate.

tissues when plasma insulin was maintained at $10 \mu \mathrm{U} / \mathrm{ml}$ plasma. Although we found that DCA changed glycogen synthesis, glycolysis and glucose oxidation at all levels of insulin studied, there was no detectable effect on muscle glucose uptake except at supraphysiologic concentrations of insulin. Thus, our results suggest that the increased glucose clearance measured by Diamond et al. (30) occurred in nonmuscle tissues.

Another interesting finding was that lactate can regulate muscle glycolysis and hence its own production. Not only was lactate release diminished in muscle of fed and fasted rats when extracellular lactate was high (Fig. 2), but in individual muscles, the rate of glycolysis was inversely proportional $(r=-0.91)$ to the rate of lactate oxidation. In contrast, the ability of lactate to suppress glycolysis was absent in muscles of rats responding to thermal injury in spite of the increased lactate oxidation (Table V). Regardless, in muscles of burned rats, DCA markedly suppressed glycolysis and increased glycogen synthesis at both physiologic and supraphysiologic concentrations of extracellular lactate.

The importance of glycogen synthesis from lactate in muscle as a means of regulating the blood lactate concentration is unclear. Studies by McLane and Holloszy (34) and Shiota et al. (12) have demonstrated that skeletal muscle from fed rats can incorporate significant amounts of lactate into glycogen when the extracellular lactate concentration is high. We confirmed this and found that this pathway was depressed by fasting (Fig. 2). Calculation of glycogen synthesis using the extracellular specific radioactivity of lactate can underestimate the rate of glycogen synthesis from lactate $(12,34)$. Measurement of the intracellular specific radioactivity of pyruvate would be preferable, but to do this accurately in muscles of the size we studied is not possible (35). Although $\left[1-{ }^{14} \mathrm{C}\right]$ lactate was used to avoid the contaminating effect of an influx of labelled carbons from tricar- bolylic acid cycle intermediates (36), it is likely that our measurements of glycogen synthesis from lactate and of lactate oxidation are underestimated because glycolysis would dilute the intracellular lactate specific activity. Regardless, this would not affect our interpretation of the metabolic effects of lactate on glucose metabolism.

Previously, we found that the rate of muscle protein degradation was positively correlated with the ratio of glycolysis (or lactate release) to glucose uptake in muscles of normal rats and rats responding to catabolic conditions $(9,25,26)$. DCA did not significantly change the rate of muscle protein degradation even though it sharply reduced this ratio. This suggests that neither increased glycolysis nor depressed glycogen synthesis account for the accelerated proteolysis associated with the response to thermal injury or uremia. The results with DCA do not eliminate the possibility that in these conditions there is a common signal affecting carbohydrate and protein metabolism independently.

In conclusion, our results indicate that the most important effects of DCA on muscle glucose metabolism are to decrease glycolysis and augment insulin-stimulated glycogen synthesis. Based on this, DCA might prove useful in catabolic states by replenishing muscle glycogen stores, increasing the efficiency of glucose utilization, and increasing the responsiveness of muscle to the metabolic effects of insulin. However, the drug also inhibits fatty acid and ketone body oxidation and branched-chain amino acid transamination in muscle $(7,37)$. To determine whether DCA exerts a net beneficial effect in catabolic conditions, additional studies will be necessary.

\section{Acknowledgments}

We thank G. Karapanos for technical assistance and P. Dolan for expert editorial assistance. 
This work was supported by grants AM-37175, AM-06660, AM20787, and AM-22125 (research training grant to the University of Virginia) from the National Institutes of Health.

\section{References}

1. Stacpoole, P. W., E. M. Harmon, S. H. Curry, T. G. Baumgartner, and R. I. Misbin. 1983. Treatment of lactic acidosis with dichloroacetate. N. Engl. J. Med. 309:390-396.

2. Park, A., and A. I. Arieff. 1982. Treatment of lactic acidosis with dichloroacetate in dogs. J. Clin. Invest. 70:853-862.

3. Graf, H., W. Leach, and A. I. Arieff. 1985. Effects of dichloroacetate in the treatment of hypoxic lactic acidosis in dogs. J. Clin. Invest. 76: 919-923.

4. Romek, S. A., and R. L. Tannen. 1986. Therapeutic benefit of dichloroacetate in experimentally-induced hypoxic lactic acidosis. J. Lab. Clin. Med. 107:378-383.

5. Whitehouse, S., R. H. Cooper, and P. J. Randle. 1974. Mechanism of activation of pyruvate dehydrogenase by dichloroacetate and other halogenated carboxylic acids. Biochem. J. 141:761-774.

6. Evans, O. B., and P. W. Stacpoole. 1982. Prolonged hypolactatemia and increased total pyruvate dehydrogenase activity by dichloroacetate. Biochem. Pharmacol. 31:1295-1300.

7. McAllister, A., S. P. Allison, and P. J. Randle. 1973. Effects of dichloroacetate on the metabolism of glucose, pyruvate, acetate, 3-hydroxybutyrate and palmitate in rat diaphragm and heart muscle in vitro and on extraction of glucose, lactate, pyruvate and free fatty acids by dog heart in vivo. Biochem. J. 134:1067-1081.

8. Goodman, M. N., N. B. Ruderman, and T. T. Aoki. 1975. Glucose and amino acid metabolism in perfused skeletal muscle. Diabetes. 27: 1065-1074.

9. Clark, A. S., R. A. Kelly, and W. E. Mitch. 1984. Systemic response to thermal injury in the rat: accelerated protein degradation and altered glucose utilization. J. Clin. Invest. 74:888-897.

10. Clark, A. S., and W. E. Mitch. 1983. A comparison of protein synthesis and degradation in incubated and perfused muscle. Biochem. J. 212:649-653.

11. Katz, J., and A. Dunn. 1967. Glucose-2-T as a tracer for glucose metabolism. Biochemistry. 6:1-5.

12. Shiota, M., S. Golden, and J. Katz. 1984. Lactate metabolism in the perfused rat hindlimb. Biochem. J. 222:281-292.

13. Ashcroft, S. J. H., L. C. C. Weerasinghe, J. M. Bassett, and P. J. Randle. 1975. The pentose cycle and insulin release in mouse pancreatic islets. Biochem. J. 126:525-532.

14. Clark, A. S., J. Fagan, and W. E. Mitch. 1985. Selectivity of the insulin-like actions of vanadate on glucose and protein metabolism in skeletal muscle. Biochem. J. 232:273-276.

15. Clark, M. G., D. P. Bloxham, P. C. Holland, and H. A. Lardy. 1973. Estimation of the fructose diphosphatase-phosphofructokinase substrate cycle in the flight muscle of Bombus affinis. Biochem. J. 134: 589-597.

16. Katz, J., P. A. Wals, S. Golden, and R. Rognstad. 1975. Recycling of glucose by rat hepatocytes. Eur. J. Biochem. 60:91-101.

17. Challis, R. A. J., J. R. S. Arch, and E. A. Newsholme. 1984. The rate of substrate cycling between fructose-6-phosphate and fructose-1,6biphosphate in skeletal muscle. Biochem. J. 221:153-161.

18. Thomas, J. A., K. K. Schlender, and J. Larner. 1968. A rapid filter paper assay for UDP glucose-glycogen glucosyltransferase, including an improved biosynthesis of UDP- ${ }^{14} \mathrm{C}$-glucose. Anal. Biochem. $25: 486-$ 489.

19. Gilboe, D. P., K. L. Larson, and F. Q. Nutall. 1972. Radioactive method for the assay of glycogen phosphorylase. Anal. Biochem. 47:2027.

20. Geller, D. 1972. ATP formation. Methods Enzymol. 2:91-92.

21. Start, C., and E. A. Newsholme. 1968. The effects of starvation and alloxan-diabetes on the contents of citrate and other metabolic intermediates in rat liver. Biochem. J. 107:411-415.

22. Roach, P. J., and J. Larner. 1976. Rabbit skeletal muscle glycogen synthase. II. Enzyme phosphorylation state and effector concentrations as interacting control parameters. J. Biol. Chem. 251:1920-1925.

23. Neely, J. R., and H. E. Morgan. 1974. Relationship between carbohydrate and lipid metabolites and the energy balance of heart muscle. Annu. Rev. Physiol. 36:413-459.

24. Newsholme, E. A., and C. Start. 1977. Regulation of carbohydrate metabolism in muscle. In Regulation in Metabolism. J. Wiley \& Sons, London. 106-130.

25. Clark, A. S., and W. E. Mitch. 1983. Muscle protein turnover and glucose uptake in acutely uremic rats: effects of insulin and the duration of renal insufficiency. J. Clin. Invest. 72:836-845.

26. May, R. C., A. S. Clark, M. A. Goheer, and W. E. Mitch. 1985. Specific defects in insulin-mediated muscle metabolism in acute uremia. Kidney Int. 28:490-497.

27. Kosow, D. P., and I. A. Rose. 1970. Product inhibition of the hexokinases. J. Biol. Chem. 245:198-204.

28. Blacksheart, P. J., P. A. H. Holloway, and K. G. M. M. Alberti. 1975. Metabolic interactions of dichloroacetate and insulin in experimental diabetic ketoacidosis. Biochem. J. 46:447-556.

29. Wells, P. G., G. W. Moore, D. Rabin, G. R. Wilkinson, J. A. Oates, and P. W. Stacpoole. 1980. Metabolic effects and pharmacokinetics of intravenously administered dichloroacetate in humans. Diabetologia. 19:109-113.

30. Diamond, M. P., J. H. Suhrer, P. E. Williams, W. W. Lacy, and A. D. Cherrington. 1982. Contribution of the liver and extrasplanchnic tissues to the hypoglycemic action of dichlo; roacetate in the conscious dog. Diabetes. 31:326-332.

31. Diamond, M. P., P. E. Williams, W. W. Lacy, and A. D. Cherrington. 1981. Effect of dichloroacetate on gluconeogenesis in vivo in the presence of a fixed gluconeogenic substrate supply to the liver. Metab. Clin. Exp. 30:880-885.

32. Stacpoole, P. W. 1977. Effect of dichloroacetate on gluconeogenesis in isolated rat hepapocytes. Metab. Clin. Exp. 26:107-116.

33. Crabb, D. W., and R. A. Harris. 1979. Mechanism responsible for the hypoglycemic actions of dichloroacetate and 2-chloropropionate. Arch. Biochem. Biophys. 198:145-152.

34. McLane, J. A., and J. O. Holloszy. 1979. Glycogen synthesis from lactate in the three types of skeletal muscle. J. Biol. Chem. 254: 6548-6553.

35. Schadewalt, P., U. Munch, M. Prengel, and W. Staib. 1983. Estimation of pyruvate decarboxylation in perfused rat skeletal muscle. Biochem. Biophys. Res. Commun. 116:456-461.

36. Olson, M. S., S. C. Dennis, M. S. DeBuysere, and A. Padma. 1978. The regulation of pyruvate dehydrogenase in the isolated perfused rat heart. J. Biol. Chem. 253:7369-7375.

37. Snell, K., and D. A. Duff. 1984. Branched-chain amino acid metabolism and alanine formation in rat diaphragm muscle in vitro. Biochem. J. 223:831-835. 